\title{
Reminiscence and item recovery in free recall
}

\author{
STEPHEN MADIGAN \\ University of Southern Califormia, Los Angeles, California 90007
}

\begin{abstract}
The item recovery or reminiscence component of recall in RTT procedures was investigated in two free recall experiments. In the first, Erdelyi and Becker's (1974) "hypermnesia" effect was found with pictures as the to-be-remembered material: total amount recalled increased over two successive test trials, and included a large reminiscence effect, with some $27 \%$ of previously unrecalled items appearing in the second test. The second experiment, with word lists, showed that the frequency of occurrence of new items was greater following a 12-min separation of two test trials than in two relatively massed tests. This kind of item recovery is relevant to models of out put interference and retrieval limitations in free recall, and may be also related to spontaneous recovery effects.
\end{abstract}

This paper describes two experiments dealing with changes in the accessibility of individual items in free recall. The studies actually resemble research described some 50 years ago by W. Brown (1923). In an early use of the RTT paradigm, Brown demonstrated that a rather large proportion (about $19 \%$ ) of items that were not recalled in an immediate test did appear in a later test, without any additional study time, and in the absence of any apparent change in the conditions of cueing. One unique feature of his data was that the NC component of recall scores (items not recalled initially, and recalled later) was greater than the $\mathrm{CN}$ (intertest forgetting) component, with the result that total amount recalled actually rose over the 30 -min interval between the two recail tests. Brown (p. 377) concluded that a single recall test "does not give an exhaustive measure of all the items remembered. Some items are remembered which are not at that particular moment recalled."

The main purpose of the present experiments was to examine some conditions affecting the occurrence of reminiscence $(\mathrm{NC})$ effects. The starting point for the research was an attempt at replication of Brown's results. Since the procedures and results are relatively simple. they will be described here, prior to a presentation of the experiments proper. A free recall RTT paradigm was used, with a list of 40 high-frequency concrete nouns. This list was tape-recorded and presented twice in a row, in two random orders, at a rate of 1 word every $3 \mathrm{sec}$. A written free recall test was then given, with $5 \mathrm{~min}$ allowed for recall. Approximately $30 \mathrm{~min}$ later, a second test was given. (Subjects had not been informed that another test would occur.) The experimental session, like Brown's, was conducted in a classroom setting, and regular lecture material filled the interval between the two tests. The subjects were

This research was supported by Grant GB-36172 from the National Science Foundation. Requests for reprints should be sent to Stephen Madigan, Department of Psychology, University of Southern California, Los Angeles. California $\mathbf{9 0 0 0 7}$
93 students in a summer school course in introductory psychology.

The mean number of words recalled in the first and second tests was 20.24 and 19.42 . This difference, of less than one item, still represents a significant loss $[t(92)=3.04, p<.005]$, and is the first point at which the results differ from Brown's. As was true of Brown's results, however, there was a considerable amount of fluctuation in the components of recall scores. The mean sizes of the CC, CN, NC, and NN components were $16.84,3.39,2.56$, and 17.18 . The mean NC score of 2.56 indicates that approximately $13 \%$ of all unrecalled items from the first test were recalled in the second test. The fact that the $\mathrm{CN}$ score was larger than the NC score accounts for the drop in total recall between the two tests. Reminiscence (NC) events were quite general across subjects. Eighty-one of the 93 subjects produced at least one such item, and only slightly more than half (48) of the subjects actually showed a drop in total recall; 20 showed a net gain and 11 no change.

This kind of demonstration is of course less than convincing, if only because of the problems of control associated with mass testing procedures in a less-than-optimal environment. Some recent studies seem to suggest that, under better controlled conditions, reminiscence effects are much less frequent. Nelson and Macloud (1974), using two immediately successive free recall trials with word lists, found that reminiscence rates were quite small, regardless of recall time or instructions to recall all items or new items only on the second test. In addition, the intertest forgetting rates exceeded the reminiscence rates, so that total amount recalled decreased on the second test trial. In general, the theoretical import of this kind of reminiscence or recovery of individual items is reduced by the infrequency of such events in repeated recall trials, especially when the possibility exists that such events are artifacts of limited recall time. It is the object of this paper to describe experimental conditions that in fact seem to produce appreciable amounts of item 
reminiscence or recovery, and to argue for the signiticance of these effects for forgetting theory.

\section{EXPERIMENT I}

The first experiment took a lead from studies reported by Erdelyi and Becker (1974) in which they found that an RTT procedure with free recall of pictures produced an absolute increase in amount recalled over the three test trials. This "hypermnesia" effect was noticeably absent with word lists. Erdelyi and Becker did not report the extent of recall tluctuations over trials, but the net gain in picture recall indicates that the $\mathrm{NC}$ rate was greater than the $\mathrm{CN}$ rate. One aim of the first experiment was to simply attempt a replication of Erdelyi and Becker's results for picture material, with an analysis of trial-to-trial changes in the components of recall scores. A second aim was to examine the effects of the kind of events occurring between successive recall tests. In one of their experiments. Erdelyi and Becker compared immediately successive test trials with conditions in which subjects had a 7-min interval between tests during which they were encouraged to "think" about list items. This latter condition produced somewhat greater recall than immediately successive test trials. In the present experiment, the two test trials were administered in immediate succession or were temporarily separated by an activity that was chosen to eliminate rehearsal or continuing attempts at recall of picture material. The point of this latter procedure was to see the extent to which test-trial separation would affect item recovery in a fashion analogous to spontaneous recovery effects in list-learning studies (Postman, Stark, \& Henschel. 1969). Number of within-list presentations of items (one or two) was also varied, following suggestions in the literature that NC rates are greater at higher levels of item availability.

\section{Method}

Design and Procedure. The two main experimental variables were number of item presentations (one or two) and interval between first and second recall trials (immediate second recall or recall following a brief period of interpolated learning). All subjects saw a set of 36 pictures-colored line drawings of common objects-for $5 \mathrm{sec} /$ presentation. Eighteen pictures were presented twice and 18 presented once, making 54 presentations in all. This sequence was divided into two blocks of 27 different items, with 18 of the first 27 presented again in the second block and 9 occurring only in the tirst block. Nine additional once-presented pictures appeared in the second block of 27 presentations. A given picture occurred equally often over the experiment as a whole as a once- or twice-presented event.

The initial study and test phases were the same for all subjects: fcllowing list presentation, free recall instructions were given (which served to dampen recency effects), and a 4-min recall period followed. Subjects wrote the names of pictures on cards, one per card. This recall test was timed. Every $15 \mathrm{sec}$, an auditory "time" signal was given and subjects marked a card and then went on to the next one to continue their recall. In the immediate retest condition. the experimenter collected the card decks, distributed new ones, and instructed subjects to attempt another recall of all the material. This final test trial had not been previously described to subjects. In the delayed retest condition, the first picture-recall trial was followed immediately by a single study-test trial on a list of 30 abstract nouns, presented auditorially. The study and test phases lasted $60 \mathrm{sec}$ each. Then instructions for the second recall were given. In both conditions, the final recall period lasted $4 \mathrm{~min}$ and was not timed. Thirty-tive subjects (USC undergraduates) were tested. in groups of up to four persons, in each of the two main conditions (inmediate or delayed second recall). The conditions were tested in an alternating sequence, with the initial condition determined randomly on each testing day.

\section{Results}

Table 1 shows mean recall scores for once- and twice-presented pictures for the immediate and delayed retest conditions. This table shows means and standard deviations for total amount recalled on each test. as well as the mean size of the intertest forgetting component $(\mathrm{CN})$ and the "reminiscence" component (NC). Recall scores for the first test appeared to represent an at least momentary exhaustion of memory; an average of only .17 twice-presented and .22 once-presented words were recalled in the last $30 \mathrm{sec}$ of recall. In each case, the modal value was easily zero.

The main result is that Erdelyi and Becker's "hypermnesia" effect was clearly replicated: total amount recalled on the second test was greater for once- and twice-presented items, in the immediate and in the delayed conditions. It is also apparent that the interpolation of the additional list in the delayed retest had little effect on recall. It seems to have perhaps slightly depressed total amount recalled for once-presented pictures, but none of the differences between conditions (for total amount recalled on the second test, mean $\mathrm{CN}$ and NC scores) are significant (p > .05).

Mean recall scores for the first and second tests were compared separately for once- and twicepresented pictures, data from the two treatment conditions combined. In both cases, the increase in recall from first to second test was significant: $\mathrm{t}(68)=$ 7.10. $p<.001$, for once-presented pictures and $t(68)$ $=4.39 . \mathrm{p}<.001$, for twice-presented pictures. This increase in amount recalled was a fairly general effect.

Table 1

Mean Total Recall and Mean $\mathrm{CN}$ and NC Scores for First $\left(\mathrm{T}_{1}\right)$ and Second $\left(T_{.2}\right)$ Recall Tests

\begin{tabular}{|c|c|c|c|c|c|c|c|c|}
\hline & \multicolumn{4}{|c|}{ One Presentation } & \multicolumn{4}{|c|}{ Two Presentations } \\
\hline & $T_{t}$ & $\mathrm{~T}_{2}$ & $\mathrm{CN}$ & $\mathrm{NC}$ & $T_{1}$ & $\mathrm{~T}_{2}$ & $\mathrm{CN}$ & NC \\
\hline \multicolumn{9}{|c|}{ Immediate $\mathrm{T}_{2}$} \\
\hline $\mathrm{m}$ & 6.80 & 8.42 & .48 & 2.11 & 10.20 & 11.34 & .94 & 2.08 \\
\hline$s$ & 2.12 & 2.75 & .50 & 1.84 & 2.12 & 2.53 & 1.21 & 1.46 \\
\hline \multicolumn{9}{|c|}{ Delayed $T_{2}$} \\
\hline$m$ & 6.40 & 7.48 & .74 & 1.82 & 10.42 & 11.74 & .82 & 2.14 \\
\hline s & 2.18 & 2.29 & .70 & 1.29 & 2.34 & 2.67 & .85 & 1.53 \\
\hline
\end{tabular}


Of the 70 subjects, 51 showed an increase in total amount recalled, 13 displayed no change, and only 6 showed a decrease.

The results also indicate an appreciable reminiscence effect in terms of the probability of recall of new items in the second test. conditionalized on nonrecall in the first test. These probabilities are .27 and .28 for twice-presented pictures in the immediate and delayed conditions, and .19 and .16 for once-presented pictures.

In both conditions, new items appearing in the second recall displayed a strong tendency to be recalled rather late in the output sequence. Over 5 ths of recall sequences, the proportions of all the new (NC) items recalled were $.09, .09, .14, .32$, and .36 for twice-presented items and $.01, .07, .11, .49$, and .32 for once-presented items. This feature of performance may, however, be partly a function of instructional conditions. In this study, subjects were encouraged to recall all items, new or old. As Nelson and Macloud (1974) have shown, subjects can as well recall new items only or presumably recall such items first if required.

In general, the results are like W. Brown's (1923) results in two ways: There was an absolute increase in amount recalled over tests, and there was also a large reminiscence component. Neither of these two effects seemed to have been modified in any way by the separation of test trial with what would seem to have been a rehearsal-preventing activity; there were no apparent interfering or facilitating effects of the interpolated learning on second-test performance. Just why picture material should be so conducive to gains in total recall and large item recovery effects is not clear. Erdelyi and Becker suggest that a possibly greater efficiency of the generate-edit process for picture as opposed to words is the basis of the effect; this explanation. however, may be most appropriate for the kind of forced-recall test they used, in which subjects had to generate 40 responses to match the number of items presented. The present experiment did not use such a procedure, and still resulted in the "hypermnesia" effect.

\section{EXPERIMENT II}

The second experiment investigated a procedure that was intended to augment reminiscence effects for verbal material. One of the features of relatively unsuccessful attempts to produce reminiscence in appreciable amounts seems to be the use of short intertest intervals. Nelson and Macloud's (1974) experiments, for example, used immediately successive recall trials, and one of the central aspects of their findings was the very low reminiscence rate for individual items, averaging about $5 \%$ across a number of conditions. Studies with longer intervals-such as W. Brown's (1923) or Birnbaum and Eichner's (1971)-seem to produce greater numbers of NC events. There are a number of reasons for thinking that increased temporal separation of test trials might increase the amount of item fluctuation. One is the possibility, suggested by Shiffrin (1970), that subjects might tend to restrict memory search across test trials to the most recently recalled set of items, instead of using a memory search defined on the original set of material. Separation of test trials might be expected to weaken this recency bias in memory search.

\section{Method}

Design and Procedure. The to-be-remembered material was a list of 36 concrete nouns. These were presented visually with a slide projector at a rate of 1 word every $3 \mathrm{sec}$ on two successive study-test cycles with randomized presentation orders of words. Each study trial was followed by a single digit-span test, intended to reduce the recency component of recall. The first two recall trials were timed, using the procedure described for Experiment I. Recall trials lasted $4 \mathrm{~min}$. Following the second test trial, subjects worked on interpolated tests (paper-and-pencil versions of judgments of numerosity and fitting puzzle parts), for 2 or $12 \mathrm{~min}$. The third and final recall trial, which had not been previously described to subjects, followed the period of interpolated activity and lasted $4 \mathrm{~min}$. This procedure constituted an RTRTT paradigm and was used to allow examination of two kinds of item recovery (NNC and CNC events). Thirty-six USC undergraduates were tested, in groups of 2 or 3,18 in each of the two conditions defined by the length of the interval between the second and third recall tests.

\section{Results}

The mean numbers of words recalled on the first and second recall tests were 12.30 and 19.92 (averaged over all 36 subjects). Once again, the 4-min recall periods seemed adequate in length, with 25 subjects recalling no items at all in the last $30 \mathrm{sec}$ of the second trial and the remaining 11 producing a total of 12 items in this period. On the third (final) test, the mean number of items recalled was 19.76 (s $=3.60)$ and $18.55(\mathrm{~s}=4.32)$ for the short and long intertest intervals. While each mean represents a drop from its corresponding value at the end of the second recall trials, the differences were not significant $(p>.10)$, nor was the difference between the two final test means $(p>.10)$. There is clearly no evidence of the kind of increase in total amount recalled that was found in the first experiment.

Table 2 shows the conditional probabilities of recall on the third test for four different patterns of recall on the first two tests. These data can be summarized as indicating that the two kinds of reminiscence or recovery events ( $\mathrm{NNC}$ and $\mathrm{CNC}$ ) increase in frequency with the longer intertest interval, while two kinds of intertest retention (NCC and CCC) decrease. Differences between the two conditions for these two kinds of recall events were tested separately and, in 


\begin{tabular}{ccccccc} 
Conditional & Probability & Table 2 \\
of & Recall on the Third & Test \\
\hline \multicolumn{5}{c}{ Recall Pattern, $\mathrm{T}_{1}-\mathrm{T}_{2}$} \\
& $\mathrm{~N}_{1} \mathrm{~N}_{2}$ & $\mathrm{C}_{1} \mathrm{~N}_{2}$ & $\mathrm{~N}_{1} \mathrm{C}_{2}$ & $\mathrm{C}_{1} \mathrm{C}_{2}$ \\
\hline \multirow{2}{*}{$\mathrm{T}_{2}-\mathrm{T}_{3}$ Interval } & $2 \mathrm{~min}$ & .080 & .396 & .810 & .901 \\
& $12 \mathrm{~min}$ & .126 & .473 & .733 & .875 \\
\hline
\end{tabular}

each case, were based on comparison of the mean numbers of such events. The mean numbers of items present in the third test, but not in the second, were $2.16(\mathrm{~s}=1.65)$ for the 2 -min intertest interval and $3.22(\mathrm{~s}=1.43)$ for the $12-\mathrm{min}$ interval, a significant difference: $t(34)=2.04, p<.01$. The mean numbers of items retained over tests (present in the second and third recalls) were $17.61(\mathrm{~s}=3.88)$ and $15.33(\mathrm{~s}=$ 4.36) for the short and long intervals, respectively. This difference was marginally significant: $t(34)=$ $1.65, .05<\mathrm{p}<.10$.

Lengthening the intertest interval also had a noticeable effect on "latency" of occurrence of new recalls (NNC events) in the final recall trial. With the 2-min intertest interval, $22 \%$ of all NCC items occurred in the first half of recall sequences; with the 12 -min interval, this figure was $48 \%$. This suggests that the late occurrence of reminiscence events in recall sequences, clearly evident in the results of the first experiment, may be characteristic only of situations with short intertest intervals.

\section{DISCUSSION}

One point to emerge from these two studies is that there are conditions under which the "reminiscence" component of RTT scores can be quite large. This was especially true in the first experiment with pictures as the to-be-remembered material: the absolute increase in amount recalled and the relative size of the NC component are hard to ignore in any account of the nature of the limitations on retrieval in free recall. In the second experiment, while the reminiscence rate for individual words was nowhere near as large, it was still larger than some figures reported in the literature (e.g., Nelson \& Macloud, 1974; Tulving, 1967) when successive recall tests were temporally separated. The effects of test trial separation also argue against the suggestion that $\mathrm{NC}$ effects are artifacts of limited initial recall periods, since the frequency of these events can be made to vary with total recall time held constant. It does seem possible to increase amount recalled by instructions that encourage subjects to continue or renew attempts at recall (Borges, 1972; Ritter \& Buschke, 1974); but such procedures do not seem necessary to produce recall of initially inaccessible material.
The most interesting aspect of the reminiscence effect for individual items is its relation to theoretical accounts for forgetting or retrieval limitations in free recall. McGeoch (1942, p. 361) offered an early account of this in these terms: "The appearance of new items in a later recall is an illustration of the phenomenon of reminiscence and may be understood in terms of a release of items from interference as a result of forgetting of erroneous and interfering responses." This implies an output interference effect in immediate recall, of the kind described by J. Brown (1968) and Rundus (1973). It also suggests the possibility of a time-dependent reduction in such interference. Some of the results of Experiment IIespecially the increased frequency of NC events, and their earlier occurrence in recall sequences in delayed retests-may be more than superficially similar to the recovery that has been attributed to the "dissipation" of response-set interference in paired-associate interference paradigms (Postman \& Underwood, 1973).

\section{REFERENCES}

Birnbaum, I. \& Eichner. J. Study versus test trials and long-term retention in free-recall learning. Joumal of Verbal Learning and Verbal Behavior, 1971, 10. 516-521.

BoRges, M. A. Increasing item accessibility in free recall. Journal of Experimental Psychology, 1972, 95, 66-71.

Brown, J. Reciprocal facilitation and impairment of free recall. Psychonomic Science, 1968, 10, 41-42.

BRown, W. To what extent is memory measured by a single recall? Journal of Experimental Psychology, 1923, 6, 337-382.

ERDELYY, M. H., \& BeCKER, J. Hypermnesia for pictures: Incremental memory for pictures but not words in multiple recall trials. Cognitive Psychology. 1974, 6. 159-171.

McGeосн, J. The psychology of human learning. New York: Longmans. Green, 1942.

Nelson, T. O., \& Maczoud, C. M. Fluctuations in recall across successive test trials. Memory \& Cognition, 1974, 2. 687-690.

Postman, L.. Stark, K., \& Henschel, D. Conditions of recovety after unlearning. Journal of Experimental Psychology Monograph, 1969, $82(1$ Pt. 2).

Postman, L., \& Underwood, B. J. Critical issues in interference theory. Memory \& Cognition, 1973, 1, 19-40.

RitTer, W., \& Buschke, H. Free, forced, and restricted recall in verbal learning. Joumal of Experimental Psychology, 1974, 103, 1204-1207.

Rundus, D. Negative effects of using list items as recall cues. Journal of Verbal Learning and Verbal Behavior, 1973, 12. 43-50.

Shiffrin, R. M. Memory search. In D. A. Norman (Ed.), Models of human memory. New York: Academic Press, 1970.

Tulving, E. The effects of presentation and recall of material in free-recall learning. Journal of Verbal Learning and Verbal Behavior, 1967. 6. 175-184.

(Received for publication May 8, 1975; revision accepted August 27, 1975.) 